\title{
Evaluation of antimalarial prescription pattern and susceptibility of Plasmodium falciparum isolates in Kaduna, Nigeria
}

\author{
O. Ifeoluwa AKANNI*, J.O. EHINMIDU and R.O. BOLAJI
}

\author{
Department of Pharmaceutical Microbiology, Faculty of Pharmaceutical Sciences, \\ Ahmadu Bello University, Zaria, Nigeria. \\ *Corresponding author; E-mail: ifeakanni@gmail.com; Tel: +234-7068133178
}

\begin{abstract}
Nigeria carries the highest burden of malaria in terms of morbidity and mortality. This is compounded by continuous resistance of Plasmodium falciparum to antimalarial drugs. This study was designed to evaluate the profile of malaria patients' antimalarial drug prescription and in vitro susceptibility of $P$. falciparum isolates to commonly prescribed antimalarial drugs in Kaduna, Nigeria. Three years' records of patients antimalarial drug prescriptions were collated (2013 to 2015) and the in vitro antimalarial agent susceptibility was determined for 28 clinical isolates using WHO Mark III microtest. Artemisinin-based combination therapy (ACT) was the most prescribed antimalarial for the period under review (92.3-93.7\%). Among the ACTs, Artemether-lumefantrine was most prescribed. Of the $28 \mathrm{P}$. falciparum isolates evaluated, $3(10.71 \%)$ were resistant to chloroquine with a median $\mathrm{IC}_{50}$ of $4.82 \mu \mathrm{M}(4.60-8.14 \mu \mathrm{M})$, while five $(17.86 \%)$ were resistant to mefloquine with a median $\mathrm{IC}_{50}$ of $25 \mu \mathrm{M}(10.3-41 \mu \mathrm{M}), 7(25.00 \%)$ to artemether with a median $\mathrm{IC}_{50}$ of $2.69 \mu \mathrm{M}$ $(2.09-8.77 \mu \mathrm{M}), 9(32.14 \%)$ to artesunate-mefloquine combination with a median $\mathrm{IC}_{50}$ of $9.0 \mu \mathrm{M}(7.98-35 \mu \mathrm{M})$ and to artesunate, $11(39.29 \%)$ were resistant with a median $\mathrm{IC}_{50}$ of $2.4 \mu \mathrm{M}(1.56-5.65 \mu \mathrm{M})$. This result shows a decline in resistance of $P$. falciparum to chloroquine compared to period prior to artemisinin-combination therapy as well as reduced susceptibility to artesunate and artemether. Further in vitro and in vivo monitoring will be required to inform antimalarial drug policy change.
\end{abstract}

(C) 2019 International Formulae Group. All rights reserved

Keywords: Antimalarial, Artemisinin-combination therapy, resistance, susceptibility, microtest.

\section{INTRODUCTION}

Malaria is a disease of wide distribution caused by Plasmodium (Lucas and Gilles, 2003). The four species infecting man namely Plasmodium falciparum, Plasmodium vivax, Plasmodium ovale and Plasmodium malariae are found mainly in tropical and subtropical regions (Shapiro and Goldberg, 2006; Wesolowski, 2015). Malaria remains a disease of major public health importance globally due to the high morbidity and mortality associated with it (WHO, 2010). Children under-five are most affected and complications such as anaemia resulting from untreated or severe malaria causes death (Ukibe et al., 2010). According to World Health Organization (WHO) recent report, 228 million cases and 405,000 deaths occurred as a result of malaria in 2018 with 93\% of these affecting Africa (WHO, 2019).

Plasmodium falciparum has been reported as the most prevalent and causes the 
most fatal malaria disease in Africa and it has been estimated to account for up to $99.7 \%$ of malaria cases in 2017 (WHO, 2018). Antimalarial drug resistance emerges as one of the greatest challenges facing malaria control today (Olaseinde et al., 2015) and recent reports of Plasmodium falciparum resistance to artemisinin and its derivatives in Cambodia threatens the control and elimination efforts (Ariey et al., 2014). Multidrug resistance of Plasmodium falciparum to commonly used drugs have been reported to weaken the therapeutic approach to the control of malaria (Ngbolua et al., 2011). Comprehensive and up-to-date understanding of the scope of antimalarial drug resistance is therefore essential for protecting the recent advances which have been attained in malaria control efforts (WHO, 2010).

Nigeria is the highest index country accounting for $25 \%$ of malaria cases and $24 \%$ of global mortality due to infections related to the most prevalent malaria parasite (WHO, 2018). It is therefore important to continue to monitor drug response of Plasmodium falciparum in different parts of Nigeria especially as cases have increased in recent reports. In vitro susceptibility testing is an epidemiological tool for assessing baseline sensitivity and for monitoring drug response provides information for early containment of drug resistance and timely revision of treatment policies (WHO, 2001). The use of artemisinin-combination therapy became effective in Nigeria in 2004. However, following reports of resistance to ACTs worldwide and Nigeria bearing the highest burden of malaria disease (WHO, 2019), monitoring for resistance becomes imperative as emergence of resistant strains of Plasmodium falciparum to currently used antimalarial drugs especially the artemisinins would further worsen the huge burden of malaria in Nigeria (WHO, 2010).

This study was designed to evaluate in vitro effectiveness of currently prescribed antimalarial agents against Plasmodium falciparum isolates from patients in Kaduna, Nigeria and to highlight the resistance factors responsible for reducing susceptibility of
Plasmodium falciparum isolates in Kaduna, Nigeria.

\section{MATERIALS AND METHODS \\ Study areas}

The study was carried out in two health facilities, Barau Dikko Teaching Hospital (BDTH) and Jowako Specialist Hospital (JSH); both Kaduna North Local Government Area of Kaduna State, Nigeria. The study was carried out from March 2016 to June 2018. Barau Dikko Teaching Hospital is a tertiary health facility while Jowako Hospital is a private health facility both located in the urban centre of Kaduna, Nigeria. Average annual rainfall is $1211 \mathrm{~mm}$ and temperature range is $19.3{ }^{\circ} \mathrm{C}-46.5{ }^{\circ} \mathrm{C}$. Hospital records of patients were accessed for antimalarial drugs prescriptions made for patients diagnosed to have the disease within the study period.

\section{Ethical considerations}

Ethical approval for the study was sought and obtained from the institutions' ethical review committees as well as individual patient's consent.

\section{Statistical analysis}

Data obtained from this study was analysed using Microsoft Excel to obtain descriptive statistics and are presented on tables.

\section{Reagents / materials used}

Antimalarial drugs: Artesunatemefloquine 600/750, artesunate, chloroquine, and artemether. RPMI1640 (Sigma Chemical company, Germany), microtitre plates, Giemsa stain, Plasmodium falciparum positive patients blood sample, ethanol/methanol, microscope slides with frosted ends, primers (k-13, Pfmdr1, PfATPase6).

\section{Study protocol and sample collection/ in vitro microtest}

Blood samples were collected from patients attending the health facility with the assistance of the medical laboratory scientists. A total of 114 patients who consented to be part of the study after informed consent was 
obtained were enrolled to participate. Male and female participants were aged 3-60 years. Blood from consenting patients with ancillary temperature above $37.5{ }^{\circ} \mathrm{C}$, mono-infection with $P$. falciparum, and parasitaemia ranging from $>1000-<80,000$ asexual parasites per $\mu 1$ of blood was used for the study. All patients who had taken any antimalarial two weeks preceding study or with any other symptoms or signs of non-malaria aetiology were excluded from the study. Blood samples which did not have the required parasitaemia were also excluded from the in vitro study. Thick and thin smears were prepared to determine species and quantitative count of parasites according to standard protocol (Cheesbrough, 2006).

Stock solutions of the following antimalarial drugs; chloroquine, mefloquine, artesunate and artemether were prepared in appropriate solvents. The solutions were then filtered aseptically in 0.22 millipore membrane filter. The solutions were further diluted to obtain working solutions. Five concentrations of working solutions were prepared in two serial dilutions and these graded concentrations of each test antimalarial agents were used to dose the 96-well flat bottomed microtitre plates aseptically. The in vitro micro-test drug susceptibility tests were carried out according to standard techniques described by Trager and Jensen (1976), and adapted Mark III micro-test (WHO, 2001) under strict aseptic conditions.

\section{Examination of the post-culture blood smears / interpretation of results}

The thick films obtained following harvesting of post-culture slides were stained using Giemsa (3\%) for 30 mins and dried for 48 hours. They were then examined with the oil immersion objectives (100X) and the number of schizonts (matured malaria parasites) were counted in each of the wells and compared with the control for every sample isolate. At the end of the incubation period, schizont maturation in the control well should be $\geq 10 \%$ per 200 asexual parasites. Where the value in the control was less than $10 \%$, such results were discarded as unsatisfactory growth.
The counts in each well were expressed as percentages of the control as shown below:

$Z=$ number of schizonts per 200 asexual parasites in control well after incubation

$\mathrm{Y}=$ number of schizonts per 200 asexual parasites in wells dosed with drugs after incubation

$\mathrm{X}=\%$ of schizonts relative to control samples

$$
\mathrm{X}(\%)=\mathrm{Y} / \mathrm{Z} \mathrm{x} 100
$$

Parasite growth inhibition for each isolate was calculated as:

Percentage schizont inhibition $=100-\mathrm{X}$

Individual percentage schizont inhibitions were fed directly into Microsoft Excel and using linear regression line analysis, their inhibitory concentrations; $\mathrm{IC}_{50}$ was determined. Drug-resistant parasites were identified as parasites with $\mathrm{IC}_{50}$ values greater than the peak plasma concentration of the antimalarial drugs used.

\section{DNA Extraction and polymerase chain reaction}

Extraction of the DNA from dried blood spots (DBS) on filter paper was carried out using the AccuPrep ${ }^{\circledR}$ Genomic DNA Extraction kit and followed Chellex-100 extraction method (Bio-Rad, USA). The DBS was cut into $1.5 \mathrm{ml}$ tubes; $200 \mu 1$ of $1 \mathrm{xPBS}$ was added into each tube and placed on a heat block at $50{ }^{\circ} \mathrm{C}$ for 1 hour. This was allowed to cool at room temperature and then vortex for 10 secs after which $20 \mu \mathrm{L}$ of Proteinase $\mathrm{K}$ was added to each of the tubes containing the sample. $200 \mu \mathrm{L}$ GB buffer was added and vortex immediately to mix. Mixture was incubated at $60{ }^{\circ} \mathrm{C}$ for 10 mins. Absolute ethanol $(400 \mu \mathrm{L})$ was added to each of the sample, (the binding columns were fixed into the collection tubes) and the lysate transferred into the upper column of the tubes and centrifuged at $8,000 \mathrm{rpm}$ for $1 \mathrm{~min}$. Washing buffer $1(500 \mu \mathrm{L})$ was added to wash and remove ethanol, centrifuged for $1 \mathrm{~min}$ and the process repeated using same volume of Washing Buffer 2. The solution from the collection was discarded after each round of wash. It was centrifuged once more at 13,000 rpm for 1 min to completely remove ethanol 
and any other droplet remaining on the collection tube.

The binding columns were then transferred to new $1.5 \mathrm{ml}$ tubes for elution by adding $50 \mu \mathrm{L}$ EA buffer and left for $1 \mathrm{~min}$ at room temperature. It was again centrifuge at $8,000 \mathrm{rpm}$ for $1 \mathrm{~min}$ to elute the DNA. The tubes containing primers were spin at 13,000 rpm for $1 \mathrm{~min}$ and reconstituted under PCR Hood using nuclease-free water and then mixed. The primers were diluted in nucleasefree water in the ratio $(10 \mu \mathrm{L}: 90 \mu \mathrm{L})$ as working solutions.

The premix for the PCR contained dNTPs, Taq polymerase, $\mathrm{MgCl}_{2}$, PCR buffer. To the premix was added $16 \mu \mathrm{L}$ nuclease-free water, $2 \mu \mathrm{L}$ primers, $2 \mu \mathrm{L}$ DNA of P.falciparum (positive control) to make a total volume of $20 \mu \mathrm{L}$. This was mixed gently till it dissolved and spun briefly to allow solution settle down in the tubes. The primers and conditions used for the molecular characterization set on the PCR machines (PTC-100 Programmable Thermal Controller, M.J research Inc.). The primers used are presented in Table 3. The products of the nested PCR were resolved by $1.5 \%$ gel electrophoresis, stained with ethidium bromide and visualized with a Bio-Rad Transluminator (Universal Hood II). The results of this were documented and are presented on Plates 1-3.

\section{RESULTS}

\section{Retrospective study}

Artemisinin-based combination therapy (ACT) was the most prescribed in the two health facilities for the period under review; Barau Dikko Teaching Hospital (92.3\%) and Jowako Specialist Hospital (93.7\%) (Table 1). Artemether-lumefantrine was most prescribed ACT (71.9\% and 59.1\%) in the public and private health facility respectively while artesunate-amodiaquine combination was the least ACT prescribed $(0 \%$ and $0.5 \%)$. Table 2 shows pattern of specific ACT prescriptions (\%). Other antimalarial drugs prescribed were artesunate $(2.7 \%$ and $3.0 \%)$, sulphadoxinepyrimethamine $(2.4 \%$ and $2.6 \%)$ and chloroquine (1.1\% and $2.1 \%$ ) from the public and private facility respectively.

\section{In vitro assay}

The degree of schizont inhibition by each of the antimalarial agents resulting in $50 \%$ inhibition of Plasmodium falciparum isolates are as presented Table 4. Of the 28 P.falciparum isolates evaluated, 3 (10.71\%) were resistant to chloroquine with a median $\mathrm{IC}_{50}$ of $4.82 \mu \mathrm{M} \quad(4.60-8.14 \mu \mathrm{M}) \quad$ while $25(89.30 \%)$ were susceptible with median IC50 of $1.85 \mu \mathrm{M}(0.49-4.33 \mu \mathrm{M})$ in tandem with the peak plasma concentration of $4.47 \mu \mathrm{M}$. Seven $(25.00 \%)$ were resistant to artemether with a median $\mathrm{IC}_{50}$ of $2.69 \mu \mathrm{M}$ $(2.09-8.77 \mu \mathrm{M})$ while twenty-one $(75.00 \%)$ were sensitive with a median $\mathrm{IC}_{50}$ of $0.62 \mu \mathrm{M}$ $(0.07-1.71 \mu \mathrm{M})$ based on the peak plasma concentration of artemether at $1.81 \mu \mathrm{M}$. Eleven $(39.29 \%)$ were resistant to artesunate with a median $\mathrm{IC}_{50}$ of $2.4 \mu \mathrm{M}(1.56-5.65 \mu \mathrm{M})$ and $17(60.70 \%)$ were sensitive with a median $\mathrm{IC}_{50}$ of $0.44 \mu \mathrm{M}(0.14-1.1 \mu \mathrm{M})$ based on a peak plasma concentration of $1.17 \mu \mathrm{M}$. Five $(17.90 \%)$ were resistant to mefloquine with a median $\mathrm{IC}_{50}$ of $25 \mu \mathrm{M}(10.3-41 \mu \mathrm{M})$ while $23(82.10 \%)$ were sensitive with a median $\mathrm{IC}_{50}$ of $1.79 \mu \mathrm{M}(0.09-9.04 \mu \mathrm{M})$ based on the peak plasma concentration of $10.0 \mu \mathrm{M}$. Nine $(32.14 \%)$ were resistant to artesunatemefloquine combination with a median $\mathrm{IC}_{50}$ of $9.0 \mu \mathrm{M}(7.98-35 \mu \mathrm{M})$ while $19(67.90 \%)$ were sensitive with a median $\mathrm{IC}_{50}$ of $2.26 \mu \mathrm{M}(0.43$ $6.09 \mu \mathrm{M})$ based on a peak plasma concentration of $1.17 / 7.9 \mu \mathrm{M}$.

\section{Drug resistance characterization}

Among the Plasmodium falciparum isolates which were resistant in vitro to the antimalarial agents tested, five isolates which exhibited in vitro resistance to artemisinins, chloroquine and mefloquine were assayed to determine the presence of molecular markers responsible for antimalarial resistance. The molecular markers of resistance assayed were P. falciparum multidrug resistant 1(Pfmdr-1), PfATPase-6 and kelch13 propeller (K-13).

Twenty per cent $(20 \%)$ of the Plasmodium falciparum isolates were observed to carry the Pfmdr-1 resistance gene 
which amplified around 600 bp and PfATPase-6 gene which amplified around 800 bp while $60 \%$ carried the K-13 gene which amplified around $850 \mathrm{bp}$. Plates 1-3 show the results of the gel electrophoresis for the detection of Pfmdr-1, Pfatpase-6 and Kelch 13 genes respectively. The presence of Pfmdr-1 gene has been implicated in quinolone resistance, e.g. chloroquine. It may also be implicated in artemisinin resistance because of cross-resistance between chloroquine, aminoalcohols (mefloquine) and artemisinins (Basco and Ringwald, 2002). Plasmodium falciparum adenosine triphosphate 6 (PfATPase6) gene; a sarco-endoplasmic reticulum $\mathrm{Ca}^{2+}$ adenosine triphosphateATPase-(SERCA) type protein is the primary target of artemisinins.

Table 1: Average pattern of antimalarial drug prescriptions (\%) in two health facilities in Kaduna, Nigeria from 2013-2015.

\begin{tabular}{|c|c|c|c|c|c|c|c|c|}
\hline \multirow[b]{2}{*}{$\begin{array}{l}\text { Drugs } \\
\text { prescribed }\end{array}$} & \multicolumn{2}{|l|}{2013} & \multicolumn{2}{|l|}{2014} & \multicolumn{2}{|l|}{2015} & \multirow{2}{*}{$\begin{array}{c}\text { Average } \\
\text { BDTH } \\
(n=325)\end{array}$} & \multirow{2}{*}{$\begin{array}{c}\text { Average } \\
\text { JSH } \\
(n=203)\end{array}$} \\
\hline & $\begin{array}{c}\text { BDTH } \\
(n=241)\end{array}$ & $\begin{array}{l}\text { JSH } \\
(n=169)\end{array}$ & $\begin{array}{c}\text { BDTH } \\
(n=354)\end{array}$ & $\underset{(\mathbf{n}=\mathbf{2 2 4})}{\text { JSH }}$ & $\begin{array}{r}\text { BDTH } \\
(\mathbf{n}=\mathbf{3 8 0})\end{array}$ & $\underset{(\mathbf{n}=\mathbf{2 1 7})}{\mathbf{J S H}}$ & & \\
\hline ACT* & 91.3 & 94.7 & 97.2 & 92.0 & 92.6 & 90.3 & 93.7 & 92.3 \\
\hline Chloroquine & 0.4 & 1.8 & 1.1 & 3.6 & 1.8 & 0.9 & 1.1 & 2.1 \\
\hline $\mathbf{S P} * *$ & 2.5 & 0.6 & 1.1 & 1.8 & 3.7 & 5.5 & 2.4 & 2.6 \\
\hline Artesunate & 5.8 & 3.0 & 0.6 & 2.7 & 1.8 & 3.2 & 2.7 & 3.0 \\
\hline
\end{tabular}

Table 2: Pattern of reported Specific ACT prescriptions in two health facilities in Kaduna, Nigeria from 2013-2015 (\%).

\begin{tabular}{|c|c|c|c|c|c|c|c|c|}
\hline \multirow{2}{*}{$\begin{array}{l}\text { Specific } \\
\text { ACT* }\end{array}$} & \multicolumn{2}{|c|}{2013} & \multicolumn{2}{|l|}{2014} & \multicolumn{2}{|c|}{2015} & \multirow{2}{*}{$\begin{array}{l}\text { Average } \\
\text { BDTH } \\
(n=305)\end{array}$} & \multirow{2}{*}{$\begin{array}{l}\text { Average } \\
\text { JSH } \\
(\mathrm{n}=187)\end{array}$} \\
\hline & $\begin{array}{c}\text { BDTH } \\
(\mathbf{n}=220)\end{array}$ & $\begin{array}{c}\text { JSH } \\
(\mathbf{n}=160)\end{array}$ & $\begin{array}{c}\text { BDTH } \\
(n=344)\end{array}$ & $\begin{array}{c}\text { JSH } \\
(n=206)\end{array}$ & $\begin{array}{c}\text { BDTH } \\
(\mathrm{n}=\mathbf{3 5 2})\end{array}$ & $\begin{array}{c}\text { JSH } \\
(n=196)\end{array}$ & & \\
\hline I & 61.8 & 58.1 & 81.3 & 49.5 & 72.7 & 69.9 & 71.9 & 59.1 \\
\hline II & 6.8 & 36.9 & 1.7 & 48.5 & 17.0 & 27.6 & 8.5 & 37.7 \\
\hline III & 23.6 & - & 14.8 & 0.5 & 7.4 & 2.0 & 15.3 & 0.8 \\
\hline IV & 0.5 & 5.0 & - & 0.5 & - & 0.5 & 0.2 & 2.0 \\
\hline $\mathbf{V}$ & 7.3 & - & 2.0 & 0.5 & 0.3 & - & 3.2 & 0.2 \\
\hline VI & - & - & - & - & 2.6 & - & 0.9 & - \\
\hline VII & - & - & - & 0.5 & - & - & - & 0.2 \\
\hline $\begin{array}{l}\text { *I= Artem } \\
\text { II= Dihyd } \\
\text { III= Artes } \\
\text { IV= Artem } \\
\text { V= Artesu } \\
\text { VI= Arten } \\
\text { VII=Artes } \\
\text { BDTH- Bc } \\
\text { JSH- Jowa }\end{array}$ & $\begin{array}{l}\text { ther lumefantr } \\
\text { oartemisinin- } \\
\text { nate- mefloqui } \\
\text { ether- mefloqu } \\
\text { nate-sulphadox } \\
\text { ether- sulphad } \\
\text { Inate-amodiaqu } \\
\text { rau Dikko Tea } \\
\text { ko Specialist H }\end{array}$ & $\begin{array}{l}\text { ne } \\
\text { iperaquine } \\
\text { le } \\
\text { ne } \\
\text { ne/pyrimetha } \\
\text { xine/pyrimetl } \\
\text { ine } \\
\text { hing Hospital } \\
\text { sppital }\end{array}$ & $\begin{array}{l}\text { ine } \\
\text { mine }\end{array}$ & & & & & \\
\hline
\end{tabular}


Table 3: Primers used and their sequence.

\begin{tabular}{llll}
\hline Gene & Primer & Sequence & Size (bp) \\
\hline Pfmdr-1 & Pfmdr-1(F) & ATGGGTAAAGAGCAGAAAGA & 603 \\
& Pfmdr-1(R) & AACGCAAGTAATACATAAAGTCA & \\
PfATPase6 & PfATPase6 1(F) & AATATTGTTATTCAGAATATGATTATAA & 896 \\
& PfATPase6 1(R) & TGGATCAATAATACCTAATCCACCTA & \\
& PfATPase6 2(F) & AGCAAATATTTTCTGTAACGATAATA & 798 \\
& PfATPase6 2(R) & TGTTCTAATTTATAATAATCATCTGT & \\
K-13 propeller & K13-out F & GGGAATCTGGTGGTAACAGA & 849 \\
& K13-out R & CGGAGTGACCAAATCTGGGA & \\
& K13-in F & GCCTTGTTGAAAGAAGCAGA & \\
& K13-in R & GCCAAGCTGCCATTCATTTG & \\
\hline
\end{tabular}

Table 4: Concentration of antimalarial agents that gave 50\% inhibition of $P$.falciparum isolates in two health facilities in Kaduna, Nigeria.

\begin{tabular}{|c|c|c|c|c|c|}
\hline S.No & $\begin{array}{l}\text { Chloroquine } \\
\text { PPL }(4.47 \mu M)\end{array}$ & $\begin{array}{l}\text { Artemether } \\
\text { PPL(1.81 } \mu \mathrm{M})\end{array}$ & $\begin{array}{l}\text { Artesunate } \\
\text { PPL }(1.17 \mu M)\end{array}$ & 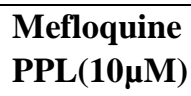 & 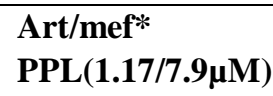 \\
\hline 1 & 0.69 & 0.62 & $0 . .41$ & 5.21 & 0.55 \\
\hline 2 & 4.82 & 0.07 & 1.86 & 1.07 & 0.66 \\
\hline 3 & 3.23 & 0.28 & 0.52 & 2.31 & 0.43 \\
\hline 4 & 2.73 & 2.69 & 4.06 & 2.74 & 2.26 \\
\hline 5 & 2.81 & 0.27 & 0.14 & 0.75 & 1.29 \\
\hline 6 & 3.15 & 2.76 & 2.53 & 1.77 & 2.20 \\
\hline 7 & 1.82 & 1.71 & 3.73 & 1.56 & 2.87 \\
\hline 8 & 3.05 & 3.07 & 2.49 & 5.09 & 3.31 \\
\hline 9 & 1.75 & 0.85 & 1.56 & 1.53 & 1.21 \\
\hline 10 & 3.56 & 0.43 & 1.96 & 0.56 & 1.77 \\
\hline 11 & 4.60 & 2.65 & 2.28 & 0.54 & 1.85 \\
\hline 12 & 3.26 & 0.75 & 2.40 & 2.09 & 2.79 \\
\hline 13 & 0.67 & 0.16 & 0.87 & 0.09 & 2.87 \\
\hline 14 & 3.56 & 2.11 & 1.97 & 1.79 & 2.26 \\
\hline 15 & 1.64 & 0.33 & 0.36 & 0.42 & 2.53 \\
\hline 16 & 1.55 & 0.8 & 0.79 & 4.07 & 8.29 \\
\hline 17 & 0.96 & 0.53 & 0.91 & 0.25 & 0.92 \\
\hline 18 & 1.85 & 1.56 & 1.10 & 35.8 & 9.70 \\
\hline 19 & 4.33 & 0.71 & 0.44 & 6.85 & 13.1 \\
\hline 20 & 0.69 & 0.34 & 0.37 & 5.57 & 8.60 \\
\hline
\end{tabular}


O. I. AKANNI et al. / Int. J. Biol. Chem. Sci. 13(7): 3398-3410, 2019

\begin{tabular}{llllll}
\hline 21 & 8.14 & 8.77 & 5.65 & 36.4 & 35.0 \\
22 & 2.10 & 0.42 & 0.44 & 41.0 & 7.98 \\
23 & 1.88 & 0.52 & 0.18 & 4.42 & 8.02 \\
24 & 0.68 & 0.7 & 0.40 & 0.61 & 8.99 \\
25 & 2.72 & 2.09 & 1.06 & 18.90 & 5.47 \\
26 & 1.33 & 1.03 & 0.94 & 10.25 & 5.25 \\
27 & 0.49 & 0.76 & 0.67 & 7.86 & 6.09 \\
28 & 1.35 & 1.36 & 0.39 & 9.04 & 9.12 \\
\%Resistance & $\mathbf{3 ( 1 0 . 7 1 )}$ & $\mathbf{7 ( 2 5 . 0 0 )}$ & $\mathbf{1 1}(\mathbf{3 9 . 2 9})$ & $\mathbf{5 ( 1 7 . 8 6 )}$ & $\mathbf{9 ( 3 2 . 1 4 )}$ \\
& & & & &
\end{tabular}

*PPL- Peak plasma level

Art/mef- artesunate- mefloquine

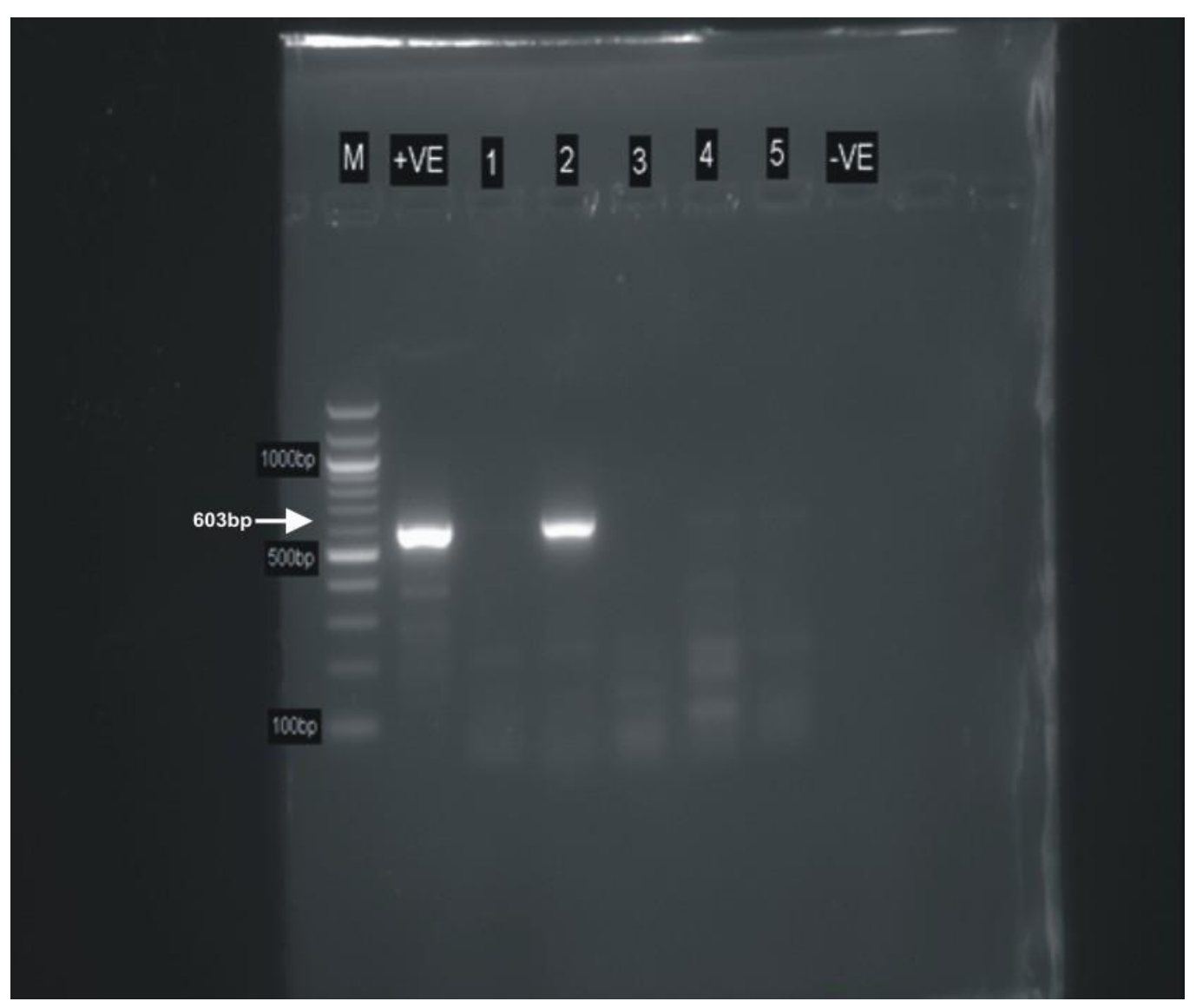

Plate 1: Amplification of Pfmdr-1 gene @ 603bp from DNA of P. falciparum isolates from patients in two hospitals in Kaduna, Nigeria.

*M=Marker

$+\mathrm{ve}=$ positive control (standard P. falciparum isolate)

$-\mathrm{ve}=$ negative control (PCR mix and water)

Nos.1-5= resistant $P$. falciparum sample isolates. 


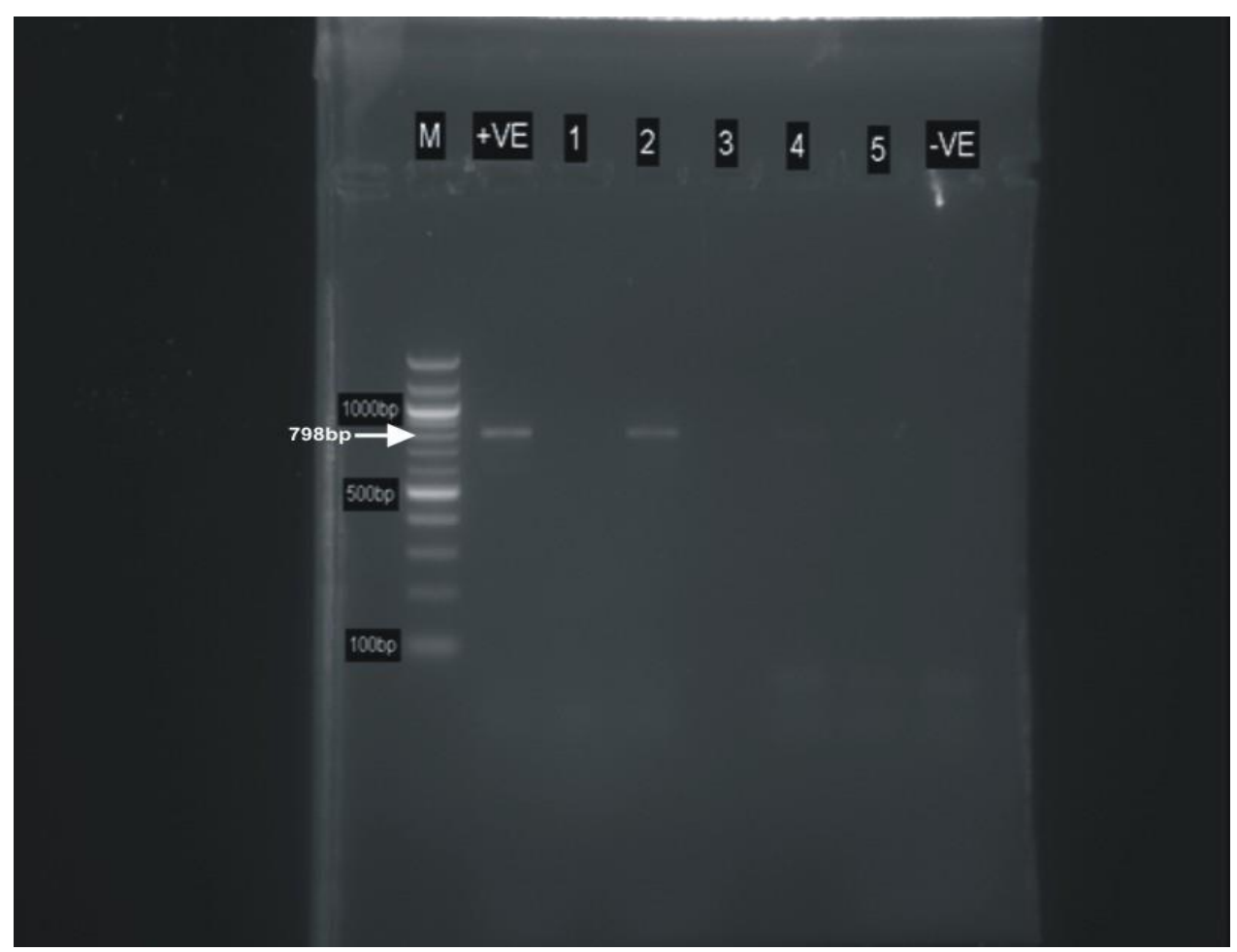

Plate 2: Amplification of Pfatpase-6 gene @ 798bp from DNA of P. falciparum infected patients in two hospitals in Kaduna, Nigeria.

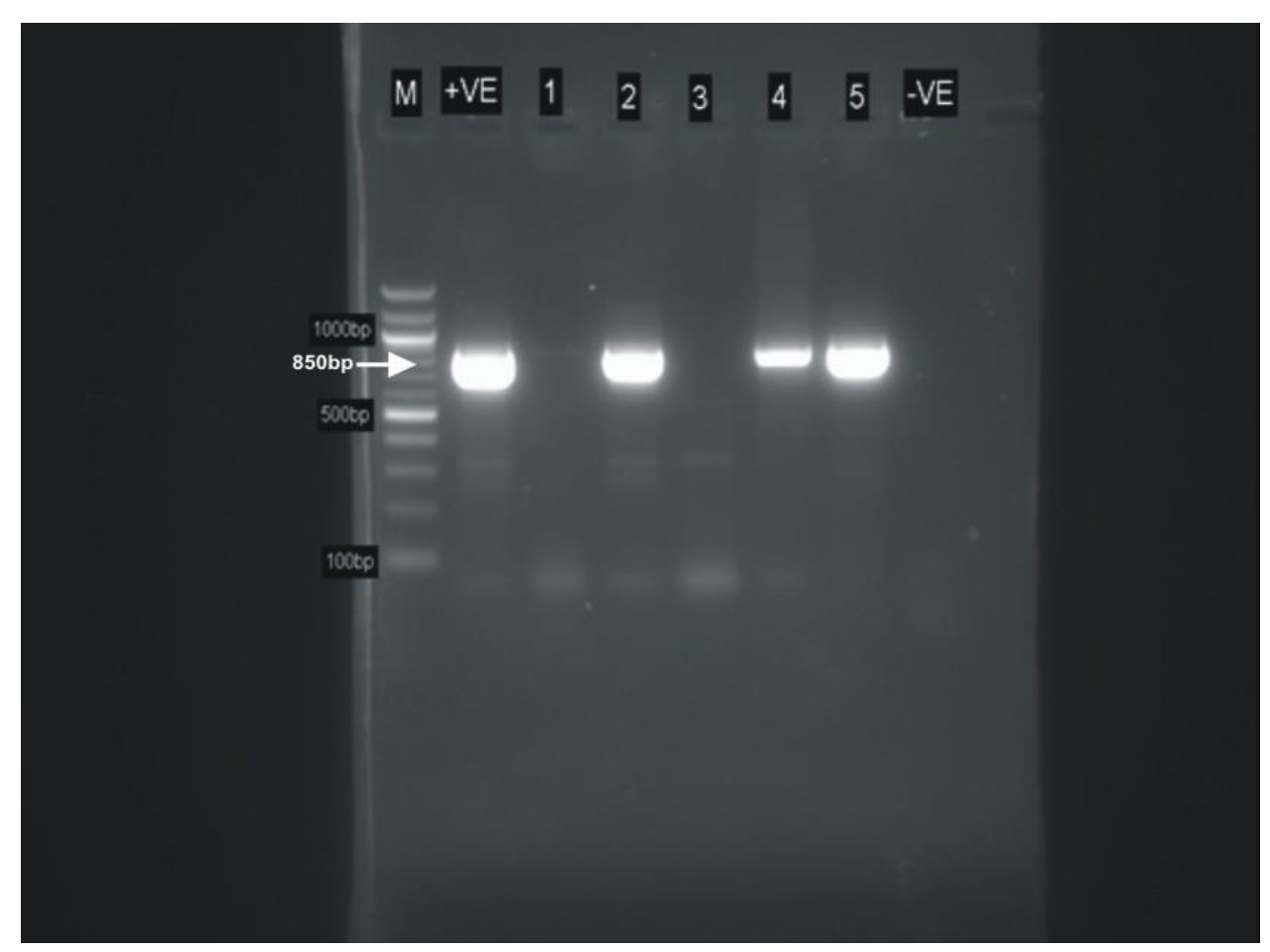

Plate 3: Amplification of Kelch 13 gene @ 850bp from DNA of P. falciparum infected patients in two hospitals in Kaduna, Nigeria. 


\section{DISCUSSION}

Observations from this study showed artemisinin combination therapy (ACT) as the most widely prescribed antimalarial; $93.7 \%$ in the public health facility and $92.3 \%$ in the private facility. Thus implying strong adherence to the antimalarial policy which had been in place in Nigeria since 2004 (FMOH, 2005). Of the ACTs, artemetherlumefantrine was mostly prescribed in both facilities (71.90/59.10\%). This is expected because the combination is a first line among all the ACT combinations adopted by the government of Nigeria for the treatment of malaria (FMOH, 2005). Artesunateamodiaquine combination was the least prescribed ACT and was recommended only in the private health facility. Howbeit, its use was very low and this may not be unrelated to factors such as adverse effects such as described by Ekong et al. (2008) who reported effects of amodiaquine on the brain macromolecules of Wistar rats. ACTs became the mainstay of antimalarial therapy following global reports of resistance to previously used antimalarial drugs such as chloroquine and sulphadoxine-pyrimethamine.

Other antimalarial drugs prescribed in order of decreasing average frequency were artesunate $\quad(2.7-3.0 \%)$, sulphadoxinepyrimethamine $(2.4-2.6 \%)$ and chloroquine $(1.1-2.1 \%)$. This is an indication that oral monotherapy is still practised. Availability of these drugs as monotherapy may constitute a continuous challenge towards eradicating drug resistant Plasmodium falciparum malaria in this region (WHO, 2014). According to WHO, availability of oral artesunate monotherapy in the private sector was highest (35\%) next to DR Congo (45.5\%) (WHO, 2014). Sulphadoxine- pyrimethamine has also been reported as commonly available over-thecounter in both rural and urban areas in Nigeria and it is the drug of choice for intermittent preventive therapy in pregnancy (IPTp) (Okeke et al., 2006; Ikpa et al., 2014).

From this study, in vitro sensitivity of

Plasmodium falciparum isolates to chloroquine was remarkably high with susceptibility of $89.3 \%$ with a median $\mathrm{IC}_{50}$ of $1.85 \mu \mathrm{M}$ and similar to the first report of decline in prevalence of chloroquine resistant parasites in Africa was in Malawi, 12 years after chloroquine was withdrawn with clinical efficacy going from less than 50\% in 1993 to $100 \%$ sensitivity by 2001 (Laufer et al., 2006). Lucchi et al. (2015) reported an increase in the in vitro sensitivity Plasmodium falciparum isolates to chloroquine following a decline in the $\mathrm{IC}_{50}$ from 2010-2013 in Western Kenya. In China, in vivo resistance to chloroquine decreased over 5-8 years from $>84 \%$ to $40 \%$ (WHO, 2014). Legrand et al (2012) reported a decline in in vitro resistance of chloroquine to an approximate $50 \%$ in French Guiana following years of chloroquine withdrawal. Kwansa-Bentum et al. (2011) found Plasmodium falciparum showed no improvement in susceptibility to chloroquine but exhibited satisfactory response to artesunate. Peletiri et al. (2012) reported $88.9 \%$ of Plasmodium falciparum isolates resistance to chloroquine of isolates in Abuja, Nigeria with a median $\mathrm{IC}_{50}$ of $0.6 \mu \mathrm{M}(0.36-$ 1.32) while Basco and Ringwald (2002) reported 59\% in vitro resistance in Cameroon. There appears to be a gradual reversal in chloroquine resistance following change in treatment policy and exclusion of chloroquine from the current antimalarial regimen. Frequent drug usage has been observed as the driving force for selection of antimalarial resistance single nucleotide polymorphisms (SNPs). Therefore, a decrease in drug pressure, e.g. chloroquine, following policy change could have helped to reduce and can further reduce resistance. Decrease in drug pressure has been reported to increase fitness cost of resistant strains thereby causing such mutant strains to lose their survival advantage (Petersen et al., 2011).

In vitro resistance of test $P$.falciparum to artesunate observed in this study was $39.3 \%$ with a median $\mathrm{IC}_{50}$ of $2.4 \mu \mathrm{M}$. This is similar to Na-Bangchang et al. (2013) who reported declining sensitivity of $P$. falciparum isolates (36.7\%) in the Thai-Myanmar border. Continued use of oral artesunate monotherapy could pose a source of resistance to the ACTs because of the presence of artesunate in the combination therapy. Such usage without a partner antimalarial agent is against WHO recommendation and has been highly discouraged. The use of oral artesunate 
monotherapy could be as a result of cost compared to the ACTs. However, continued use of oral artesunate monotherapy poses a threat to the therapeutic life of the ACTs and malarial control (WHO, 2014).

Resistance of test $P$. falciparum isolates to artemether in vitro was $25 \%$ with a median $\mathrm{IC}_{50}$ of $2.69 \mu \mathrm{M}$. This is quite similar to Pradines et al. (1998) who reported $14 \%$ decline in $P$. falciparum susceptibility to artemether while Badru (2017) reported 100\% sensitivity. The antimalarial, artemether is recommended in combination with lumefantrine in fixed dose as drug of choice for treatment of uncomplicated malaria. It is also available as oily injection for intramuscular administration, the form in which it is often used as monotherapy.

The degree of in vitro resistance of test $P$. falciparum isolates to mefloquine observed in this study was $17.86 \%$ with a median $\mathrm{IC}_{50}$ of $25 \mu \mathrm{M}$. This result is comparable with that of Yavo et al. (2010) where in Cote d'Ivoire a $15.2 \%$ in vitro resistance was observed. In Senegal, Fall et al. (2011) reported reduced $P$. falciparum isolates susceptibility of $50 \%$ to mefloquine even though the drug was not in the ACT combination in Senegal at the time of the study and in 2015 prevalence of $P$. falciparum isolates with decreased susceptibility to mefloquine remained high at $55.6 \%$. Although mefloquine is part of the ACT recommended for treatment of uncomplicated malaria, its use is low. The low level of use of mefloquine could be the reason for increased susceptibility to mefloquine probably as a result of reduced drug pressure.

Five of the $P$. falciparum isolates which were found to be resistant to all the classes of test antimalarial agents in this study were subjected to Polymerase Chain Reaction (PCR) to determine the presence of molecular markers responsible for resistance to the drugs. One of the $P$. falciparum isolates (20\%) clearly displayed Pfmdr-1 which amplified at 603bp. Lucchi et al. (2015) reported a prevalence of Pfmdr-1 of $18 \%$ in 2010 and 0\% in 2013 in Western Kenya. Antony et al. (2016) also found low association (degree of association not specified) of Pfmdr-1 to chloroquine resistance following PCR and sequencing. In this study, the proportion of
Pfmdr-1 may not be considered as low because of the size of sample used.

In this study, PfATPase6 was clearly amplified in $20 \%$ of the isolates around 798bp. Jambou et al. (2005) in a study in three countries, reported presence of PfATPase- 6 mutation exclusively in French Guiana but none was reported in Senegal and Cambodia while Saha et al. (2013) in India observed a pattern of PfATPase-6 inconsistent with that associated with decrease in vitro susceptibility to artemether of field isolates from French Guiana. The role of PfATPase6 with respect to resistance of $P$. falciparum to artemisinins will require further research.

Kelch 13 propeller gene was amplified in $60 \%$ of $P$. falciparum isolates at around 850bp. This shows that most the isolates carried the k-13 gene. However, Dama et al. (2017) reported a low frequency of K13 propeller mutations of $<2 \%$ while Ariey et al. (2014) reported that the mutations associated with prolonged parasite clearance time following the use of ACTs in Cambodia and other South East (SE) Asian countries were not observed in Mali. From recent studies in Africa, only one has reported the presence of K13 propeller SNPs associated with artemisinin resistance found in SE Asia (JID, 2016).

\section{Conclusion}

From this study, there was increased susceptibility of test Plasmodium falciparum isolates to chloroquine while sensitivity of the test $P$. falciparum isolates to the artemisinins used in the study showed reduced sensitivity. Also, oral artesunate and chloroquine as well as sulphadoxine-pyrimethamine monotherapy were still prescribed as observed from this study. Molecular markers for resistance to the antimalarial drugs to which $P$. falciparum isolates were tested were amplified among resistant isolates. However, this study involved a rather small sample size upon which results obtained are based. We therefore encourage further surveillance involving larger sample size and sequencing of the resistant genes that may be observed. Periodic surveillance using therapeutic efficacy tests and in vitro susceptibility tests 
should be carried out to obtain early signal of impending antimalarial drug resistance.

\section{COMPETING INTERESTS}

The authors declare that they have no competing interests.

\section{AUTHORS' CONTRIBUTIONS}

Study was designed and supervised by JOE and co-supervised by ROB while the experiments were carried out and the write up and analysis done by OIA.

\section{ACKNOWLEDGEMENTS}

Corresponding author hereby acknowledge Mr Emmanuel (who assisted in the micro-test and in the reading of the microscope slides), $\mathrm{Mr}$ Ezekiel of the department of pharmaceutical microbiology, Ahmadu Bello University, Zaria; Medical Laboratory Scientists; Mrs Funke Oladipo, Mrs Charity, Late Mrs Jane Musa, Mr Ayuba and Mercy (Barau Dikko Teaching Hospital) for their assistance.

\section{REFERENCES}

Antony HA, Das S, Parija SC, Padhi S. 2016. Sequence Analysis of Pfcrt and Pfmdr1 genes and its association with chloroquine resistance in Southeast Indian Plasmodium falciparum isolates. Genom Data., 8: 85-90. DOI: 10.10161j.data.2016.04.010.

Ariey F, Witkowski B, Amaratunga C, Beghain J, Langlois A, Khim N. 2014. A molecular marker of artemisinin-resistant Plasmodium falciparum malaria. Nature, 505 (7481): 50-55. DOI: 10.1038 /nature 12876 .

Badru M. 2017. Antimalarial susceptibility of Plasmodium falciparum isolates in Wusasa, Zaria. Theses.

Basco LK, Ringwald P. 2002. Molecular epidemiology of malaria in Cameroon.X. Evaluation of PFMDR1 Mutations as Genetic Markers for resistance to aminoalcohols and artemisinin derivatives. American Journal of Tropical Medicine and Hygiene, 66(6): 667-671.

DOI: 10.4269/ajtmh.2002.66.667.
Becaye F, Diawara S, Sow K, Baret E, Diatta B, Khadidiatou BF, Pape S Mbaye, Fatou F, Diemme Y, Rogier C, Wade B, Bercion R, Pradines B. 2011. Ex vivo susceptibility of Plasmodium falciparum isolates from Dakar, Senegal, to seven standard antimalarial drugs. Malaria Journal, 10: 310. DOI: 10.1186/14752875-10-310

Bustamante C, Folarin OA, Gbotosho GO, Batista CN, Mesquita EA, Brindeiro RM, Happi CT. 2012. In vitro reduced susceptibility of artemether in Plasmodium falciparum and its association with polymorphisms on transporter genes. The Journal of Infectious Diseases, 206: 324-32. DOI: 10.1093/infdis/jis359.

Dama S, Niangaly H, Ouattara A, Sagara I, Sissoko S, Traore O.B, Djimbe AA. 2017. Reduced ex vivo Susceptibility of Plasmodium falciparum after oral artemether-lumefantrine treatment in Mali. Malaria Journal, 16: 59. DOI: 10.1186/s12936-017-1700-8

Ekong MB, Igiri A O, Ekanem TB, Egwu OA. 2008. The effect of amodiaquine on some macromolecules of Wistar rats. International Journal of Biological and Chemical Sciences, 2(4): 434-438.

FMOH. 2005. Federal Ministry of Health. Nigeria Ikpa TF, Sha'a KK, Auta IK. 2014. Molecular markers of sulphadoxine-pyrimethamine resistant malaria prior to intermittent preventive treatment among pregnancies in Makurdi, Nigeria. International Journal of Biological and Chemical Sciences, 8(5): $\quad$ 1961-1968. DOI: 10.4314/ijbcs.v8i5.1

Jambou R, Legrand E, Niang M, Khim N, Lim P, Volney B, Ekala MT, Bouchier C, Esterre P, Fandeur T, MercereauPuijalon O. 2005. Resistance of Plasmodium falciparum field isolates to in vitro artemether and point mutations of the SERCA-type PfATPase6. Lancet, 366 (9501): 1960-1963.

JID. 2016. Is the A578S Single Nucleotide Polymorphism in K-13-propeller a marker of Emerging Resistance to Artemisinin among Plasmodium 
falciparum in Africa? Editorial. The Journal of Infectious Diseases Correspondence, 213: 165-166.

Kwansa-Bentum B, Ayi I, Suzuki T, Otchere J, Kumagai T, Anyan WK, Ohta T. 2011. Plasmodium falciparum isolates from Southern Ghana exhibit polymorphisms in the SERCA-type PfATPase though sensitive to artesunate in vitro. Malaria Journal, 10: 187.

Laufer MK, Travassos MA. 2009. Resistance to Antimalarial Drugs: Molecular, Pharmacological and Clinical considerations. Paediatric Research, 65 (5 Pt.2): 64R-70R DOI: 10.1203/PDR.0b013e3181a0977e

Legrand E, Yrinesi J, Ekala M, Peneau J, Volney B, Berger F, Mercereau-Puijalon O. 2012. Discordant Temporal evolution of Pfcrt and Pfmdr1 genotypes and Plasmodium falciparum in vitro drug susceptibility to 4-aminoquinolines after drug policy change in French Guiana. Antimicrobial Agents and Chemotherapy, 1382-1389. DOI: 10.1128/AAC.05280-11.

Adetokunbo LO, Herbert GM. 2003. Short Textbook of Public Health Medicine for the Tropics (Revised 4th Edn). Hodder Arnold: London.

Lucchi NW, Komino F, Okoth S A, Goldman I, Onyona P, Wiegand RE, Kariuki S. 2015. In vitro and molecular surveillance for antimalarial drug resistance in Plasmodium falciparum parasites in western Kenya reveals sustained artemisinin sensitivity and increased chloroquine sensitivity. Antimicrobial Agents and Chemotherapy, 59: 7540-7547. DOI: 10.1128/AAC.01894-15

Na-Bangchang K, Muhamad P, Ruaengweerayut R, Chaijaroenkul W, Karbwang J. 2013. Identification of Resistance of Plasmodium falciparum to artesunate-mefloquine combination in an area along Thai-Myanmar border: Integration of clinico-parasitological response, systemic drug exposure and in vitro parasite sensitivity. Malaria Journal, 12: 263.
Ngbolua KN, Rafatro H, Rakotoarimanana H, Ratsimamanga US, Mudogo V, Mpiana PT, Tshibangu DST. 2011. Pharmacological screening of some traditionally-used antimalarial plants from the Democratic republic of Congo compared to their ecological taxonomic equivalence in Madagascar. International Journal of Biological and Chemical Sciences, 5(5): 1797-1804. DOI: 10.4314/ijbcs.v5i5.3

Olaseinde GI, Ojurongbe DO, Akinjogunla OJ, Egwari LO, Adeyeba AO. 2015. Prevalence of malaria and predisposing factors to antimalarial drug resistance in Southwestern Nigeria. Research Journal of Parasitology, 10(3): 92-101. DOI: 10.3923/jp.2015.92.101

Peletiri I, Matur B, Ibecheozor N, Ihongbe J, Wakama T. 2012. In vitro susceptibility of Plasmodium falciparum to Antimalarial drugs in Abuja, Nigeria. The Internet Journal of Parasitic Diseases, 5(1). ispub.com

Petersen I, Eastman R, Lanzer M. 2011. Drugresistant malaria: Molecular mechanisms and implications for public health. FEBS Lett., $\quad \mathbf{5 8 5}(11)$ : 1551-1562. DOI: 10.1016/j.febslet.2011.04.042

Pradines B, Mabika Mamfoumbi M, Parzy D, Owono Medang M, Lebeau C, Mourou Mbina JR, Kombila M. 1998. In vitro susceptibility of Gabonese wild isolates of Plasmodium falciparum to artemether, and comparison with chloroquine, quinine, halofantrine and amodiaquine. Parasitology, 117 (Pt. 6): 541-5. https://www.ncbi.nlm.nih.gov

Saha P, Naskar A, Ganguly S, Das S, Guha SK, Biswas A, Maji AK. 2013. Therapeutic efficacy of artemisinin combination therapies and prevalence of S769N mutation in PfATPase6 gene of Plasmodium falciparum in Kolkata, India. Asian Pacific Journal of Tropical Medicine, 2013: 443-448.

Shapiro TA, Goldberg DE. 2006. Chemotherapy of Parasitic Infections. In Goodman \& Gilman's The Pharmacological Basis of Therapeutics. $\left(11^{\text {th }}\right.$ Edn). McGraw-Hill Medical 
Publishing Division: New York; 10211047.

Trager W, Jensen JB. 1976. Human malaria parasites in continuous culture. Science, 193: 673-675.

Ukibe NR, Onyenekwe CC, Ahaneku JI, Meludu SC, Ukibe SN, Ilika A, Ifeanyi M, Igwegbe AO, Ezeani M, Onochie A, Ofiaeli N. 2010. Packed cell volume and serum iron in subjects with HIV-malaria co-infection in Nnewi, South-Eastern Nigeria. International Journal of Biological and Chemical Sciences, 4(2): 471-478.

Wesolowski R. 2015. Plasmodium knowlesi as a threat to global public health. Korean $J$ Parasitol, 53(5): 575-581. DOI: 10.3347/kjp.2015.53.5.575

World Health Organization 2001. In vitro micro-test (Mark III) for the assessment of the response of Plasmodium falciparum to chloroquine, mefloquine, quinine, amodiaquine, sulfadoxinepyrimethamine and artemisinin. Instructions for use of the in vitro microtest kit (Mark III). World Health Organization, CTD/MAL/97.20.2.2001.

World Health Organization 2010. Global report on antimalarial drug efficacy and drug resistance: 2000-2010. World Health Organization, 2010.

WHO (World Health Organization). 2014. Withdrawal of oral artemisinin-based monotherapies. In: Emergence and spread of artemisinin resistance calls for intensified efforts to withdraw oral artemisinin-based monotherapy from market. Global Malaria Programme WHO/HTM/GMP/2014.3. Accessed from www.who.int

WHO (World Health Organization). 2018. World Malaria Report 2018. https://www.who.int

WHO (World Health Organization). 2019. World Malaria Report 2019. https://www.who.int

Yavo W, Bla KB, Djaman AJ, Assi SB, Basco LK, Mazabraud A, Kone M. 2010. In vitro Susceptibility of Plasmodium falciparum

to monodesethylamodiaquine, quinine, mefloquine and halofantrine in Abidjan (Cote d'Ivoire). African Health Science, 10(2): 111-116. Accessed from https://www.ncbi.nlm.nih.gov. 